\title{
Patient Knowledge and Qualities of Treatment Decisions for Localized Prostate Cancer
}

\author{
Lisa M. Daum, BS, Elyse N. Reamer, MPH, Julie J. Ruterbusch, MPH, Joe Liu, MD, \\ Margaret Holmes-Rovner, PhD, and Jinping Xu, MD, MS
}

Background: Controversy surrounds treatment for localized prostate cancer (LPC).

Objectives: To assess men's localized prostate cancer (LPC) knowledge and its association with decision-making difficulty, satisfaction and regret.

Methods: Population-based sample of 201 men (104 white, 97 black), $\leq 75$ years with newly diagnosed LPC completed a self-administered survey.

Results: Mean age was 61 $( \pm 7.6)$ years; two-thirds had less than a Bachelor's degree. Mean LPC knowledge was low, $5.87( \pm 2.53$, maximum score 11). More than a third of men who received surgery or radiation did not know about serious long-term treatment side effects. Fewer than half of the men correctly answered comparative side effect and survival benefit questions between surgery and radiation. Knowledge gaps were greatest among black men, men with lower education, single men. Tumor aggressiveness (i.e. PSA level, Gleason score) and treatment choice were not associated with knowledge. Knowledge was not associated with decisional satisfaction or regret. However, greater knowledge was associated with greater decision-making difficulty $(P=.018)$.

Conclusions: Significant LPC knowledge gaps existed across groups, with greater knowledge gaps among black men. The association of decision-making difficulty with knowledge was independent of race. Better patient education is needed, but may not alleviate men's decision-making difficulty due to inherent scientific uncertainty. (J Am Board Fam Med 2017;30:288-297.)

Keywords: Decision Making, Prostate Cancer

Prostate cancer is the second most common cancer among men in the United States, and 1 in 7 men will be diagnosed with prostate cancer during his lifetime. ${ }^{1}$ African American men are disproportion-

This article was externally peer reviewed.

Submitted 17 September 2016; revised 12 January 2017; accepted 12 January 2017.

From the Department of Family Medicine and Public Health Sciences (ENR, JX), Department of Oncology (JJR), and Department of Anesthesiology (JL), Wayne State University School of Medicine (LMD), Detroit, MI; and the Department of Medicine, Michigan State University, East Lansing (MH-R).

Funding: This study was supported by a Mentored Research Scholar Grant in Applied and Clinical Research (grant MRSGT-06-133-01-CPPB; primary investigator, JX) from the American Cancer Society.

Prior presentation: Part of these results was presented at the Annual Michigan Family Medicine Research Day, Howell, MI (May 2014).

Conflict of interest: none declared.

Corresponding author: Jinping $\mathrm{Xu}, \mathrm{MD}, \mathrm{MS}$, Department of Family Medicine and Public Health Sciences, Wayne State University School of Medicine, 3939 Woodward Avenue, 3rd Floor, Detroit, MI 48021 (E-mail: jxu@ med.wayne.edu). ately affected by prostate cancer, with regard to both incidence and mortality. ${ }^{2}$ While a variety of treatment options are available for localized prostate cancer (LPC), many of them have high risks of serious side effects such as urinary leakage, bowel urgency, and erectile dysfunction. To date, no study has proven that any 1 treatment improves survival over the others, leading to much controversy in choosing the best treatment for an individual patient. ${ }^{3,4}$

Because of the significant trade-offs among various available treatment options for LPC, ${ }^{5}$ most professional guidelines recommend a shared decision-making process between physicians and patients to ensure a treatment choice that is truly patient-centered and to maximize decisional satisfaction and minimize decision-making difficulty and regret. ${ }^{6,7}$ This process requires that patients have adequate knowledge about the natural history of LPC and the pros and cons of all available treatment options. However, previous studies have 
found that many patients with LPC, including African Americans, lack a complete understanding of prostate cancer and the potential side effects associated with various treatment options. ${ }^{8-11}$ Poor prostate cancer knowledge has been associated with increased decisional conflict, increased uncertainty, and decreased perceived decision-making effectiveness. ${ }^{11}$ Men who were more knowledgeable about prostate cancer treatment options have shown increased satisfaction with their treatment decision than less knowledgeable men. ${ }^{12}$ Identifying men who have less knowledge and/or higher decisionmaking difficulty in the clinical setting may allow for targeted support. However, few studies exist to guide physicians in determining which patients are at risk for higher decision-making difficulty.

We conducted this study of patients with newly diagnosed LPC to assess their knowledge during the process of deciding on a treatment, and whether knowledge score was associated with decision-making difficulty, satisfaction, and regret in a racially and socioeconomically diverse population. We hypothesized that significant knowledge gaps would exist in different racial and socioeconomic groups, and that less knowledgeable men would experience greater decision-making difficulty, along with less satisfaction and more regret with their treatment decision.

\section{Methods}

We conducted a population-based, cross-sectional survey of black and white men aged $\leq 75$ years, living in the Detroit metropolitan area, and newly diagnosed with LPC between 2009 and 2010. The study methods, sampling, and survey instrument have been previously reported. ${ }^{13}$ Briefly, new LPC cases were identified by Rapid Case Ascertainment in the Metropolitan Detroit Cancer Surveillance System, a population-based cancer registry that is part of the National Cancer Institute's Surveillance, Epidemiology, and End Results program. If the patient's physician stated the patient was healthy enough to participate, the eligible patient was mailed a self-administered survey with a small (\$10) monetary incentive. The method described by Dillman ${ }^{14}$ was used to encourage survey response. To reduce the burden on participants, the survey was divided into 2 parts, which were mailed to participants approximately 1 month apart. The first part of the survey asked men to report their treatment choice, reasons for the choice, and what treatment options were offered and recommended by their physicians. ${ }^{13}$ The second half of the survey asked about the information sources, LPC knowledge, and decisional experiences and outcomes (ie, decision-making difficulty, satisfaction, and regret). ${ }^{15,16}$ LPC was defined as T1 to T2 tumors based on American Joint Committee on Cancer staging criteria. The study received approval from the institutional review board at Wayne State University.

\section{Sampling}

During the study period, a total of 874 potentially eligible patients with LPC were identified. To achieve similar numbers of white and black men, they were sampled at a ratio of 1:3, leaving a total of 559 men sampled for study contact. After initial physician and patient contact, 168 total patients were excluded from the study (118 because their physicians did not approve their participation and 50 because they did not meet all study inclusion criteria), resulting in 391 eligible cases to be surveyed. ${ }^{13}$ Of these, 266 men completed the first part of the survey-a response rate of $68 \%$. Another 22 men declined to participate in the second survey. Therefore, a total of 244 men were sent the second part of the survey, and 201 men completed it, for a response rate of $82 \%$.

\section{Instruments and Measures}

The primary outcome variables were the number of questions answered correctly on the 11-item LPC knowledge scale and the 3 decisional measures. Since we could not find a published validated LPC knowledge scale, we developed our own based on a through review of the literature and qualitative studies. ${ }^{9,10}$ The knowledge scale consisted of 11 statements about the natural history of LPC and its treatment options (eg, comparative side effect profiles, facts and myths) using the options "true," "false," or "do not know" (Table 1). Each correct answer was scored with 1 point, and the total knowledge score was the sum of all correct answers. "Do not know" was considered an incorrect answer for statistical analysis. The treatment decisionmaking experiences and outcomes (ie, decisionmaking difficulty, satisfaction, and regret scales) were based on existing scales, modified for our study. ${ }^{15,17,18}$ (Scales are available upon request.) 
Table 1. Response to Knowledge Statement by Race and Treatment $(\mathrm{N}=192)$

\begin{tabular}{|c|c|c|c|c|c|c|c|c|}
\hline \multirow[b]{2}{*}{ Knowledge Statement* } & \multirow[b]{2}{*}{$\begin{array}{c}\text { Overall } \\
(\mathrm{n}=192)\end{array}$} & \multicolumn{3}{|c|}{ Race } & \multicolumn{4}{|c|}{ Treatment } \\
\hline & & $\begin{array}{c}\text { White } \\
(\mathrm{n}=102)\end{array}$ & $\begin{array}{c}\text { Black } \\
(\mathrm{n}=90)\end{array}$ & $P$ Value & $\begin{array}{l}\text { AS/WW } \\
(\mathrm{n}=16)\end{array}$ & $\begin{array}{l}\text { Radiation } \\
(\mathrm{n}=53)\end{array}$ & $\begin{array}{l}\text { Surgery } \\
(\mathrm{n}=96)\end{array}$ & $P$ Value \\
\hline $\begin{array}{l}\text { There are several ways to treat early } \\
\text { stage prostate cancer successfully. } \\
\text { (True) }\end{array}$ & 89.6 & 92.2 & 86.7 & .18 & 93.8 & 92.5 & 89.6 & .71 \\
\hline $\begin{array}{l}\text { If men live long enough, most will } \\
\text { have cancer cells in their prostate, } \\
\text { but few will die of prostate } \\
\text { cancer. (True) }\end{array}$ & 69.3 & 78.4 & 58.9 & .01 & 87.5 & 77.4 & 63.5 & .06 \\
\hline $\begin{array}{l}\text { Treatment for prostate cancer can } \\
\text { have serious long-term side } \\
\text { effects. (True) }\end{array}$ & 64.6 & 72.5 & 55.6 & .03 & 62.5 & 54.7 & 70.8 & .20 \\
\hline $\begin{array}{l}\text { In the early stage, doctors can't } \\
\text { always tell how your prostate } \\
\text { cancer will act. (True) }\end{array}$ & 62.5 & 67.6 & 56.0 & .22 & 81.3 & 54.7 & 67.7 & .19 \\
\hline $\begin{array}{l}\text { Most prostate cancers grow very } \\
\text { slowly and rarely cause problems. } \\
\text { A few grow quickly. (True) }\end{array}$ & 58.9 & 67.6 & 48.9 & .02 & 56.3 & 54.7 & 63.5 & .54 \\
\hline $\begin{array}{l}\text { Having surgery on a cancer } \\
\text { increases the possibility that the } \\
\text { cancer will spread to other parts } \\
\text { of the body. (False) }\end{array}$ & 50.5 & 59.8 & 40.0 & .01 & 37.5 & 35.8 & 65.6 & $<.01$ \\
\hline $\begin{array}{l}\text { Surgery leads to more urinary } \\
\text { incontinence side effects (leaking } \\
\text { urine) than radiation. (True) }\end{array}$ & 47.9 & 44.1 & 52.2 & .19 & 31.3 & 52.8 & 52.1 & .24 \\
\hline $\begin{array}{l}\text { Surgery leads to more sexual side } \\
\text { effects (inability to have erections) } \\
\text { than radiation. (True) }\end{array}$ & 44.3 & 46.1 & 42.2 & .88 & 43.8 & 47.2 & 44.8 & .87 \\
\hline $\begin{array}{l}\text { Having radiation as the first } \\
\text { treatment can make it difficult for } \\
\text { doctors to perform surgery if the } \\
\text { cancer came back later. (True) }\end{array}$ & 41.1 & 54.9 & 25.6 & $<.01$ & 25.0 & 34.0 & 53.1 & .02 \\
\hline $\begin{array}{l}\text { Radiation leads to more bowel } \\
\text { problems (leaking stool or rectal } \\
\text { bleeding) than surgery. (True) }\end{array}$ & 37.5 & 42.2 & 32.2 & .23 & 25.0 & 34.0 & 41.7 & .38 \\
\hline $\begin{array}{l}\text { The chance of being alive } 10 \text { years } \\
\text { after treatment is the same for } \\
\text { surgery as it is for radiation. } \\
\text { (True) }\end{array}$ & 35.4 & 45.1 & 24.4 & $<.01$ & 31.3 & 52.8 & 29.2 & .01 \\
\hline
\end{tabular}

Data are the percentages of correct responses, unless otherwise indicated. Bold values in table indicate the difference was "statistically significant".

*True and false answers are based on our knowledge scale.

AS, active surveillance; WW, watchful waiting.

When asking about men's sources of information about prostate cancer and its treatment options, the 12-item questions were grouped into 2 categories: 3 items related to physician sources (ie, urologist, radiation oncologist, and primary care physician [PCP]) and 9 items for nonphysician sources (ie, spouse/partner, relatives, friends, the Internet, health pamphlets/brochures, place of worship, TV/radio/newspaper, magazines/books, and informational videos). The total number of the 9 nonphysician information sources was counted based on the number of affirmative responses for each item; this was used as 1 of the predictors for the knowledge score. Other predictors considered were age, race, education, marital status, insurance, tumor characteristics (ie, prostate-specific antigen [PSA], Gleason score), and treatment choice. Selfreported PSA and Gleason score were used when available and supplemented with values in the Metropolitan Detroit Cancer Surveillance System. Other missing data were omitted, and no imputation was attempted.

\section{Statistical Analysis}

The distribution of study variables was described using counts and percentages. The knowledge 
score was compared between races and among treatment options using the Fisher exact test. The unadjusted effects of study variables on knowledge score were examined using linear regression. Although insurance type was significantly associated with knowledge score in the unadjusted analysis, it was not included in the multivariable linear regression model because of its high colinearity with age. All other significant predictors in the unadjusted analysis were included in a multivariable linear regression model, in addition to age and treatment choice, which were considered a priori. We then used the knowledge score as the predictor of the 3 decisional outcome measures (ie, decision-making difficulty, satisfaction, and regret) in adjusted and unadjusted analyses. Because of the lack of variability in the Likert-scale responses for decisional satisfaction and regret, the 3 decisional measures were dichotomized, with the median as the cutoff. Logistic regression was used for the associations between knowledge score and the 3 decisional measures, which were adjusted for the significant factors demonstrated in the unadjusted model. All analyses were computed using $\mathrm{R}$ version 3.1.2 ( $\mathrm{R}$ Development Core Team, Vienna, Austria), with a $P$ value $<.05$ considered significant.

\section{Results}

Among the total sample of 201 men (104 white and 97 black), the average age was 61.5 years (range, 43-75 years; standard deviation [SD], 7.3 years), and $90 \%$ of the men had a high school education or more (Table 2). The mean knowledge score was low for both races (mean, 5.87; SD, 2.5; range, $0-11$ ), but was lower for black men compared with white men (mean $\pm \mathrm{SD}, 5.00 \pm 2.51$ vs $6.68 \pm$ 2.29; $P<.001$ ) for questions regarding the natural history of LPC and the comparative survival rate and side effect profile between the 2 major treatment options-surgery and radiation. In fact, black men consistently scored lower than white men on all questions except for 1 . For example, only $64.6 \%$ of men $(72.5 \%$ of white men vs $55.6 \%$ of black men; $P=.03$ ) endorsed the statement, "Treatment for prostate cancer can have serious long-term side effects," whereas only $58.9 \%$ (67.6\% of white men vs $48.9 \%$ of black men; $P=.02)$ endorsed the statement, "Most prostate cancers grow very slowly and rarely cause problems. A few grow quickly." Less than $50 \%$ of the men correctly answered the
Table 2. Characteristics of Study Sample $(\mathrm{N}=201)$

\begin{tabular}{|c|c|}
\hline & Patients \\
\hline \multicolumn{2}{|l|}{ Age, years } \\
\hline$<65$ & $123(61)$ \\
\hline$\geq 65$ & $78(39)$ \\
\hline \multicolumn{2}{|l|}{ Race } \\
\hline Black & $97(48)$ \\
\hline White & $104(52)$ \\
\hline \multicolumn{2}{|l|}{ Married/partnered } \\
\hline Yes & $151(77)$ \\
\hline No & $46(23)$ \\
\hline \multicolumn{2}{|l|}{ Education } \\
\hline$<$ High school & $18(9)$ \\
\hline High school graduate/some college & $113(57)$ \\
\hline College graduate or more & $68(34)$ \\
\hline \multicolumn{2}{|l|}{ Gleason score } \\
\hline$\leq 6$ & $97(49)$ \\
\hline 7 & $78(39)$ \\
\hline$\geq 8$ & $24(12)$ \\
\hline \multicolumn{2}{|l|}{ Prostate-specific antigen (ng/mL) } \\
\hline$\leq 4$ & $77(39)$ \\
\hline $4.1-<10$ & $87(45)$ \\
\hline $10-<15$ & $13(7)$ \\
\hline$\geq 15$ & $18(9)$ \\
\hline \multicolumn{2}{|l|}{ Insurance } \\
\hline Private & $154(78)$ \\
\hline Nonprivate & $43(22)$ \\
\hline \multicolumn{2}{|l|}{ Treatment } \\
\hline Active surveillance & $17(9)$ \\
\hline Surgery & $99(54)$ \\
\hline Radiation & $53(29)$ \\
\hline Other & $16(9)$ \\
\hline Knowledge, mean (SD) & $5.87(2.5)$ \\
\hline Information sources, mean (SD) & $3.94(2.5)$ \\
\hline
\end{tabular}

Data are $\mathrm{n}(\%)$ unless otherwise indicated. Some of the numbers may not add to the total $(\mathrm{N}=201)$ because of missing values. $\mathrm{SD}$, standard deviation.

questions regarding the comparative side effect profiles of surgery and radiation and their associated 10-year survival rates (Table 1). Interestingly, men who chose surgery answered correctly significantly more often for questions addressing the effect of radiation on future surgery and the effect of surgery on cancer spread compared with men who chose radiation. By contrast, men who chose radiation were more likely than men who chose surgery to endorse the statement, "The 10-year survival rates are the same for surgery and radiation" (Table 1). Men reported that the top 3 most commonly used information sources were urologists, PCPs, and pamphlets. The mean number of 
Figure 1. Information sources used when seeking knowledge of prostate cancer. Mags/Bks, magazines/books; PCP, primary care physician; Rad Onc, radiation oncologist.

\section{Proportion of Patients Using Each Information Source}

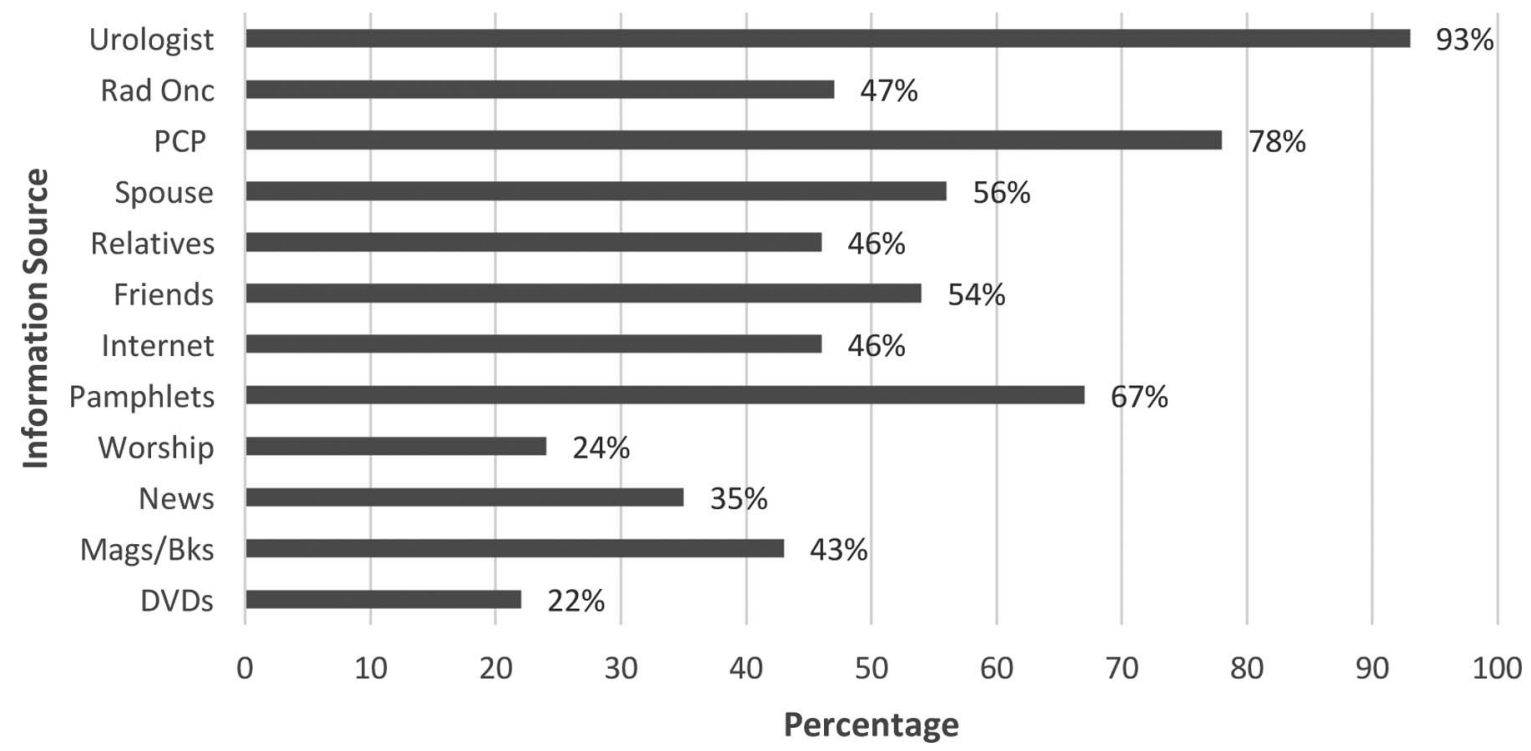

information sources used (other than seeing physicians) was 3.94 (range, 0-9; SD, 2.5) (Figure 1).

In unadjusted analysis, race, education, marital/ partner status, PSA level, insurance type, and the number of information sources used were significantly associated with LPC knowledge score (Table 3), whereas age and Gleason score were not. A borderline significant association exists between treatment choice and knowledge score, suggesting that men who chose surgery may have more knowledge compared with men who chose other options $(P=.06)$. In the multivariable linear regression analysis, race, marital/partner status, education, and the number of information sources used remained statistically significant (Table 4). We did not include insurance type in the model because of its high correlation with age, which is adjusted in the model.

Table 3. Effect of Unadjusted Variables on Prostate Cancer Knowledge Score

\begin{tabular}{lccc}
\hline Variable & Unadjusted Estimate & $95 \%$ CI & $P$ Value* \\
\hline Age & -0.49 & -1.19 to 0.22 & .17 \\
Race (reference: white) & -1.47 & -2.13 to -0.82 & $<.001$ \\
Married/partnered & 1.93 & $1.16-2.70$ & $<.001$ \\
Education & 1.39 & $0.85-1.92$ & $<.001$ \\
Gleason score & -0.38 & -0.89 to 0.13 & .14 \\
PSA level & -0.38 & -0.75 to -0.01 & $\mathbf{. 0 4 6}$ \\
Insurance (reference: private) & -2.29 & -3.04 to -1.53 & $\mathbf{< 0 1}$ \\
Treatment (reference: surgery) & & & .06 \\
$\quad$ AS/WW & -0.73 & -1.98 to 0.52 & .25 \\
$\quad$ Radiation & -0.61 & -1.41 to 0.18 & .13 \\
$\quad$ Other & -1.61 & -2.90 to -0.32 & $\mathbf{. 0 1}$ \\
Information sources, $n$ & 0.27 & $0.13-0.40$ & $<.001$ \\
\hline
\end{tabular}

Bold values in table indicate the difference was "statistically significant".

${ }^{*}$ Linear regression analysis.

AS, active surveillance; CI, confidence interval; PSA, prostate-specific antigen; WW, watchful waiting. 
Table 4. Effect of Adjusted Variables on Prostate Cancer Knowledge Score*

\begin{tabular}{lccc}
\hline Variable & Adjusted Estimate* & $95 \%$ CI & $P$ Value $^{\dagger}$ \\
\hline Age & -0.32 & -0.98 to 0.34 & .34 \\
Race (reference: white) & -0.75 & -1.42 to -0.08 & $\mathbf{. 0 3}$ \\
Married/partnered & 1.44 & $0.61-2.27$ & $\mathbf{0 0 1}$ \\
Education & 0.94 & $0.40-1.48$ & $\mathbf{< . 0 0 1}$ \\
PSA Level & -0.16 & -0.51 to 0.19 & .37 \\
Treatment (reference: surgery) & & & .42 \\
$\quad$ AS/WW & -0.48 & -1.63 to 0.68 & .41 \\
$\quad$ Radiation & -0.45 & -1.17 to 0.28 & .23 \\
$\quad$ Other & -0.70 & -1.91 to 0.52 & .26 \\
Information sources, n & 0.20 & $0.07-0.34$ & $\mathbf{. 0 0 3}$ \\
\hline
\end{tabular}

Bold values in table indicate the difference was "statistically significant".

*Adjusted for race, marriage, education, age, prostate-specific antigen (PSA) level, and treatment choice.

${ }^{\dagger}$ Linear regression analysis.

AS, active surveillance; CI, confidence interval; WW, watchful waiting.

Study participants were highly satisfied with (on a scale of $1-5$; median score, 5 ; $\mathrm{SD}, 0.43)$ and did not regret (on a scale of $1-5$; median score, 1 ; SD, 0.83 ) their treatment choice. However, the decision-making difficulty score varied across the spectrum of 1 to 5 , with a median of 2.6 (SD, 0.43 ). In both unadjusted and adjusted analyses, higher knowledge score was not significantly associated with either decisional satisfaction or regret. However, higher knowledge score was significantly associated with increased decision-making difficulty (Table 5).

\section{Discussion}

In this population-based cohort of black and white men with newly diagnosed LPC, we found that the majority of men had significant knowledge deficits regarding the natural history of prostate cancer and the comparative side effect profiles and survival benefit among 2 major treatment options: surgery and radiation. More than a third of the men who received surgery or radiation treatment did not know that these treatments can have serious longterm side effects. Fewer than half of the men correctly answered questions regarding the common side effect profile and survival benefit of surgery compared with radiation. As we hypothesized, significant knowledge gaps existed among different racial and socioeconomic groups, with lower knowledge among black men, men with less education, men who were not married or partnered, and men who consulted fewer information sources. Neither tumor aggressiveness (ie, PSA level, Gleason score) nor treatment choice was associated with overall LPC knowledge score. Furthermore, the knowledge score was not associated with decisional satisfaction or regret. Contrary to our hypothesis, we found that a higher LPC knowledge score was associated with greater decision-making difficulty.

Few studies to date have directly analyzed differences in LPC knowledge among a population with a high proportion of African Americans, as we have here. A previous study of African American

Table 5. Effect of Prostate Cancer Knowledge Score on Decision-Making Difficulty, Satisfaction, and Regret

\begin{tabular}{lcccc}
\hline Decisional Measure & Unadjusted OR $(95 \% \mathrm{CI})$ & $P$ Value $^{\dagger}$ & Adjusted OR* $(95 \% \mathrm{CI})$ & $P$ Value \\
\hline Satisfaction & $0.88(0.78-1.00)$ & .06 & $0.88(0.75-1.03)$ & .12 \\
Regret & $1.02(0.91-1.15)$ & .72 & $1.10(0.94-1.27)$ & .24 \\
Difficulty & $1.14(1.01-1.29)$ & .04 & $1.26(1.07-1.49)$ & .007 \\
\hline
\end{tabular}

Bold values in table indicate the difference was "statistically significant".

*Adjusted for race, marriage, education, age, prostate-specific antigen level, and treatment choice

${ }^{\dagger}$ Logistic regression analysis.

CI, confidence interval; OR, odds ratio. 
men without prostate cancer supports our finding that a higher education level and being married are associated with more prostate cancer knowledge. ${ }^{19}$ In a recent study of mainly white, college-educated men with LPC, using a knowledge questionnaire similar to ours, Orom et $\mathrm{a}^{12}$ found a higher average knowledge score in their sample $69 \%$ correct, compared with $53 \%$ correct in our study). As the survey questions were similar, the difference in study populations likely accounts for the difference in knowledge and supports the validity of our scale, since the 2 measures behaved consistently, given the differences in populations. ${ }^{12}$

The large knowledge gaps we found regarding the side effect profiles and survival benefits of different treatment options implies that men who choose radiation or surgery did so with important misunderstandings of the likely results and side effects of their treatment choice. Patients' information about prostate cancer and its treatment options comes from many sources, including both physician and nonphysician sources; the most frequent was a urologist, as we found in this study and others. ${ }^{20}$ Nonphysician sources of information, such as family, friends, and the Internet, may contribute to both overall attitudes toward cancer in general and prostate cancer information in particular. However, the finding that men lacked detailed knowledge of side effect profiles and the effect of treatment alternatives on survival is consistent with our earlier report that these patients had unrealistic expectations of the survival benefit of active treatment. ${ }^{13}$ Whatever the source of the knowledge gap, our findings demonstrate that black men, less educated men, and unmarried men are vulnerable groups that may need more support and information from their health care providers when making their treatment decisions about LPC. This is particularly true for black men, who are disproportionately affected by higher prostate cancer incidence and mortality, as well as decisional regret and lower quality of life after treatment. ${ }^{21,22}$

We found that consulting more information sources beyond physicians significantly increased men's knowledge of LPC. Similar results were found in another study that showed that information-seeking behavior was associated with more knowledge of prostate cancer. ${ }^{19}$ Many cancer patients have reported that accurate and unbiased information about treatment options for cancer and their side effects is difficult to find. ${ }^{23}$ This may contribute to the large deficit in prostate cancer knowledge observed in our study, among both lower socioeconomic groups and the overall study population. Increased accessibility to comprehensive and accurate, unbiased information about prostate cancer beyond health care providers may improve men's knowledge before making this important and difficult treatment decision. Targeting increased access to unbiased resources or welldesigned educational decision aids for vulnerable populations such as African Americans or less educated men may help to address the disparities in LPC knowledge identified in our study. This may provide a basis for them to make informed treatment decisions that are concordant with their treatment goals and preferences, provided they get adequate support from their physicians.

Importantly, PCPs were found to be the second most commonly used source for prostate cancer knowledge, after urologists. This suggests opportunities for PCPs to provide unbiased information during the critical treatment decision-making time, as the literature suggests that specialists are more likely to be biased toward whatever options they deliver themselves. ${ }^{24,25}$ Use of a survey such as ours to evaluate patients' prostate cancer knowledge may be useful in identifying those who will benefit most from resources and educational materials. As the physicians with whom patients likely share the closest and most long-term doctor-patient relationship, PCPs are well positioned to play an active role in helping men acquire adequate LPC knowledge and alleviate decisional burden. PCPs should make men aware of the equipoise in LPC treatment options and reassure them that the speed with which they make this decision will not affect mortality or morbidity. They should explain the importance of taking time to contemplate and discuss with all providers the side effects that matter most to them. Patients' ideas, concerns, and expectations about the options, their benefits, and their harms should be elicited, and patients should be supported in the process of deliberation. This could be achieved by using a 3 -step model, ${ }^{26}$ with short tools such as "option grids" to initiate shared decision making during clinical encounters, and then referring patients to more extensive tools (eg, booklets, webbased decision aids) to read and share with family members. These brief tools are designed to facilitate a dialog about options but do not attempt to be comprehensive. ${ }^{27}$ Well-designed patient "decision 
aids" that clearly describe the options available and their possible benefits and harms are available and could be used before or after office visits to encourage specific and in-depth communication. ${ }^{28,29}$ While PCPs may not be experts in LPC treatment options, they are often very knowledgeable about the patient's comorbidities, functional status, decision-making style, and preferences, and should be a crucial part of the multidisciplinary team supporting the patient through this stressful time.

Decision-making difficulty, a measure of the distress and uncertainty surrounding a treatment choice and the patient's confidence in that decision, measures the level of anxiety and stress for men and their families during the process of making a treatment decision after being diagnosed with LPC. While additional educational efforts and increased access to information sources may increase men's knowledge of LPC, these efforts might not be enough to decrease decision-making difficulty. Contrary to our initial hypothesis, we found that increased knowledge of LPC was associated with increased decision-making difficulty. We think this result is plausible since so many controversies and uncertainties exist surrounding the myriad treatment options for LPC and a lack of consensus even among experts regarding the best decision..$^{9,10,13}$ Another possible explanation is that when men's overall knowledge of treatment side effects and survival benefit is so low, it may not reach the threshold at which a positive impact on decisionmaking difficulty can be observed. In fact, Orom et $\mathrm{al}^{12}$ also reported that increased knowledge of LPC was associated with greater decision-making difficulty.

Few data exist to help clinicians identify which patients are at risk for decision-making difficulty so that they can be targeted for supportive interventions. Although high-quality evidence shows that decision aids for people facing treatment or screening decisions in general, compared with usual care, improve people's knowledge regarding options and reduce their decisional conflict related to feeling uninformed and unclear about their personal values, only low-quality evidence indicates that they improve congruence between the chosen option and the patient's values. ${ }^{30}$ A recent systemic review of LPC decision aids found them to have only a small positive impact on decisional regret, knowledge, decisional conflict, and satisfaction with a treatment decision. ${ }^{31}$ Our findings suggest that current efforts to increase knowledge of LPC, such as educational interventions and increased access to information sources, may not be enough to effectively decrease decision-making difficulty. Better patient education with unbiased, evidence-based information is necessary, but it may not be sufficient to minimize decision-making difficulty because of the current controversies over and uncertainties of predicting clinically significant cancers from indolent cancers. Interventions may need to reassure men that everyone finds this decision difficult, and that there is no 1 best choice for everyone. Literacy levels among patients may be low, and cultural factors may require communication strategies that are more inclusive of family and friends, particularly among less educated African American men. Men also need to be reassured that most LPC grows slowly, and they do not have to rush to a decision. In the future, more reliable methods, such as novel biomarkers that can guide men's treatment decisions by differentiating aggressive cancers that need to be treated from indolent cancers that can be observed, are needed to decrease men's decision-making difficulty. In the meantime, physicians play a critical role in helping patients make decisions that are consistent with their own health care objectives, including both realistic life expectations and the side effects of treatment options. $^{5}$

Strengths of this study include that it is one of few population-based studies that examine the relationships between personal, racial, clinical, and treatment characteristics and men's knowledge of LPC, as well as associations between knowledge and decision-making difficulty, decisional satisfaction, and regret. However, our study has several limitations. First, a smaller number of patients $(\mathrm{n}=$ 17/201) chose watchful waiting or active surveillance (AS). Larger studies are needed to confirm our findings in this group of men. In addition, we did not differentiate watchful waiting from AS in this study because these terms are often used interchangeably by both physicians and patients. Second, as this survey was done during 2009 to 2010, it likely underrepresents AS in current practice. However, the main treatment options, their possible benefits and harms, and the controversies surrounding the best treatment for individuals are not changed. Third, some variables may have been misclassified because of self-reported data; such bias would not likely have differed significantly between 
the different demographic groups within our study. In addition, the high correlations between selfreported PSA and Gleason score and those reported in the tumor registry gave us confidence in the reliability of the self-reported data. Our data were skewed toward high satisfaction and low regret with treatment decisions, with little variability. This may limit the study in delineating any associations between knowledge and decisional satisfaction or regret. This could also be a result of the short amount of time between making a treatment choice and filling out our survey. Longer-term studies with larger populations may be needed to further explore this relationship. Since no validated knowledge scale about LPC is available in the literature, we constructed our own knowledge scale based on the literature and qualitative studies., ${ }^{9}, 10,32$ Finally, our data were from 1 geographic location that may not be representative of other locations.

\section{Conclusion}

This racially diverse, population-based study provides important new information on the effects of patient demographic and tumor characteristics, and of information sources, on men's knowledge of LPC, as well as the effect of that knowledge on decisional outcome measures, particularly decisionmaking difficulty. Overall, we found a very low level of knowledge of LPC among the majority of men, and more information sources used beyond physicians significantly increased men's knowledge of LPC. However, more knowledge of LPC was associated with increased difficulty regarding making an LPC treatment decision. These findings underscore the importance and necessity of better patient education to increase knowledge of LPC, but it may not alleviate men's decision-making difficulty because of the current scientific uncertainty in this area.

To see this article online, please go to: http://jabfm.org/content/ 30/3/288.full.

\section{References}

1. American Cancer Society. Key statistics for prostate cancer. 2017. Available from: http://www.cancer.org/ cancer/prostatecancer/detailedguide/prostate-cancerkey-statistics. Accessed March 23, 2017.

2. Centers for Disease Control and Prevention. Prostate cancer rates by race and ethnicity. Reviewed August 20, 2015; updated June 16, 2016. Available from: http://www.cdc.gov/cancer/prostate/statistics/ race.htm. Accessed September 25, 2016.

3. Hamdy FC, Donovan JL, Lane JA, et al. 10-Year outcomes after monitoring, surgery, or radiotherapy for localized prostate cancer. N Engl J Med 2016; 375:1415-24.

4. Wilt TJ, MacDonald R, Rutks I, Shamliyan TA, Taylor BC, Kane RL. Systematic review: comparative effectiveness and harms of treatments for clinically localized prostate cancer. Ann Intern Med 2008;148:435-48.

5. Donovan JL, Hamdy FC, Lane JA, et al. Patientreported outcomes after monitoring, surgery, or radiotherapy for prostate cancer. N Engl J Med 2016; 375:1425-37.

6. Mohler J, Bahnson RR, Boston B, et al. NCCN clinical practice guidelines in oncology: prostate cancer. J Natl Compr Canc Netw 2010;8:162-200.

7. Thompson I, Thrasher JB, Aus G, et al. Guideline for the management of clinically localized prostate cancer: 2007 update. J Urol 2007;177:2106-31.

8. Snow SL, Panton RL, Butler LJ, et al. Incomplete and inconsistent information provided to men making decisions for treatment of early-stage prostate cancer. Urology 2007;69:941-5.

9. Xu J, Dailey RK, Eggly S, Neale AV, Schwartz KL. Men's perspectives on selecting their prostate cancer treatment. J Natl Med Assoc 2011;103:468-78.

10. Xu J, Neale AV, Dailey RK, Eggly S, Schwartz KL. Patient perspective on watchful waiting/active surveillance for localized prostate cancer. J Am Board Fam Med 2012;25:763-70.

11. Kaplan AL, Crespi CM, Saucedo JD, Connor SE, Litwin MS, Saigal CS. Decisional conflict in economically disadvantaged men with newly diagnosed prostate cancer: baseline results from a shared decision-making trial. Cancer 2014;120:2721-7.

12. Orom H, Biddle C, Underwood W, 3rd, Nelson CJ, Homish DL. What is a "good" treatment decision? Decisional control, knowledge, treatment decision making, and quality of life in men with clinically localized prostate cancer. Med Decis Making 2016; 36:714-25.

13. Xu J, Janisse J, Ruterbusch J, Ager J, Schwartz KL. Racial differences in treatment decision-making for men with clinically localized prostate cancer: a population-based study. J Racial Ethn Health Disparities 2016;3:35-45.

14. Dillman D. Mail and telephone surveys. New York: John Wiley and Sons; 1978.

15. Holmes-Rovner M, Kroll J, Schmitt N, et al. Patient satisfaction with health care decisions: the satisfaction with decision scale. Med Decis Making 1996; 16:58-64.

16. Steginga SK, Occhipinti S. The application of the heuristic-systematic processing model to treatment decision making about prostate cancer. Med Decis Making 2004;24:573-83. 
17. Orom H, Penner LA, West BT, Downs TM, Rayford $W$, Underwood $W$. Personality predicts prostate cancer treatment decision-making difficulty and satisfaction. Psychooncology 2009;18:290-9.

18. Connolly T, Reb J. Regret in cancer-related decisions. Health Psychol 2005;24(4 Suppl):S29-34.

19. Ross L, Dark T, Orom H, et al. Patterns of information behavior and prostate cancer knowledge among African-American men. J Cancer Educ 2011; 26:708-16.

20. Holmes-Rovner M, Montgomery JS, Rovner DR, et al. Informed decision making: assessment of the quality of physician communication about prostate cancer diagnosis and treatment. Med Decis Making 2015;35:999-1009.

21. Hu JC, Kwan L, Krupski TL, et al. Determinants of treatment regret in low-income, uninsured men with prostate cancer. Urology 2008;72:1274-9.

22. Jenkins R, Schover LR, Fouladi RT, et al. Sexuality and health-related quality of life after prostate cancer in African-American and white men treated for localized disease. J Sex Marital Ther 2004;30: 79-93.

23. Harper FW, Nevedal A, Eggly S, Francis C, Schwartz K, Albrecht TL. "It's up to you and God": understanding health behavior change in older African American survivors of colorectal cancer. Transl Behav Med 2013;3:94-103.

24. Fowler FJ, Jr., McNaughton Collins M, Albertsen PC, Zietman A, Elliott DB, Barry MJ. Comparison of recommendations by urologists and radiation on- cologists for treatment of clinically localized prostate cancer. JAMA 2000;283:3217-22.

25. Bill-Axelson A, Holmberg L, Garmo H, et al. Radical prostatectomy or watchful waiting in early prostate cancer. N Engl J Med 2014;370:932-42.

26. Elwyn G, Frosch D, Thomson R, et al. Shared decision making: a model for clinical practice. J Gen Intern Med 2012;27:1361-7.

27. Elwyn G, Lloyd A, Joseph-Williams N, et al. Option grids: shared decision making made easier. Patient Educ Couns 2013;90:207-12.

28. Michigan Cancer Consortium. Making the choice: deciding what to do about prostate cancer. Available from: http://www.prostatecancerdecision.org. Accessed December 28, 2016.

29. Agency for Healthcare Research and Quality. Knowing your options: a decision aid for men with clinically localized prostate cancer. Available from: https:// www.effectivehealthcare.ahrq.gov/ehc/decisionaids/ prostate-cancer/. Accessed December 28, 2016.

30. Stacey D, Legare F, Col NF, et al. Decision aids for people facing health treatment or screening decisions. Cochrane Database Syst Rev 2014;(1): CD001431.

31. Violette PD, Agoritsas T, Alexander P, et al. Decision aids for localized prostate cancer treatment choice: systematic review and meta-analysis. CA Cancer J Clin 2015;65:239-51.

32. Rees C, Abed R, Sheard C. Development of a reliable and valid questionnaire to test the prostate cancer knowledge of men with the disease. Patient Educ Couns 2003;51:285-92. 